\title{
Anxiety sensitivity in adolescents: Factor structure and relationships to trait anxiety and symptoms of anxiety disorders and depression
}

Citation for published version (APA):

Muris, P. E. H. M., Schmidt, H. G., Merckelbach, H. L. G. J., \& Schouten, E. (2001). Anxiety sensitivity in adolescents: Factor structure and relationships to trait anxiety and symptoms of anxiety disorders and depression. Behaviour Research and Therapy, 39(1), 89-100. https://doi.org/10.1016/S00057967(99)00179-5

Document status and date:

Published: 01/01/2001

DOI:

10.1016/S0005-7967(99)00179-5

Document Version:

Publisher's PDF, also known as Version of record

Please check the document version of this publication:

- A submitted manuscript is the version of the article upon submission and before peer-review. There can be important differences between the submitted version and the official published version of record.

People interested in the research are advised to contact the author for the final version of the publication, or visit the DOI to the publisher's website.

- The final author version and the galley proof are versions of the publication after peer review.

- The final published version features the final layout of the paper including the volume, issue and page numbers.

Link to publication

\footnotetext{
General rights rights.

- You may freely distribute the URL identifying the publication in the public portal. please follow below link for the End User Agreement:

www.umlib.nl/taverne-license

Take down policy

If you believe that this document breaches copyright please contact us at:

repository@maastrichtuniversity.nl

providing details and we will investigate your claim.
}

Copyright and moral rights for the publications made accessible in the public portal are retained by the authors and/or other copyright owners and it is a condition of accessing publications that users recognise and abide by the legal requirements associated with these

- Users may download and print one copy of any publication from the public portal for the purpose of private study or research.

- You may not further distribute the material or use it for any profit-making activity or commercial gain

If the publication is distributed under the terms of Article $25 \mathrm{fa}$ of the Dutch Copyright Act, indicated by the "Taverne" license above, 


\title{
BEHAVIOUR
}

RESEARCH AND

THERAPY

Shorter communication

\section{Anxiety sensitivity in adolescents: factor structure and relationships to trait anxiety and symptoms of anxiety disorders and depression}

\author{
Peter Muris ${ }^{\mathrm{a},{ }^{*}}$, Henk Schmidt ${ }^{\mathrm{b}}$, Harald Merckelbach ${ }^{\mathrm{b}}$, Erik Schouten ${ }^{\mathrm{a}}$ \\ ${ }^{a}$ Department of Medical, Clinical and Experimental Psychology, Maastricht University, PO Box 616, 6200 MD, \\ Maastricht, The Netherlands \\ ${ }^{\mathrm{b}}$ Department of Experimental Psychology, Maastricht University, Maastricht, The Netherlands
}

\begin{abstract}
The current study examined the anxiety sensitivity construct in a large sample of normal Dutch adolescents aged 13-16 years $(n=819)$. Children completed the Childhood Anxiety Sensitivity Index (CASI; Silverman, W. K., Fleisig, W., Rabian, B. \& Peterson, R. A. (1991). Journal of Clinical Child Psychology, 20, 162-168) and measures of trait anxiety, anxiety disorder symptoms and depression. Results showed that (1) anxiety sensitivity as indexed by the CASI seems to be a hierarchically organized construct with one higher-order factor (i.e., anxiety sensitivity) and three or four lower-order factors, (2) anxiety sensitivity and trait anxiety were strongly correlated, (3) anxiety sensitivity was substantially connected to symptoms of anxiety disorders (in particular of panic disorder and agoraphobia) and depression, and (4) anxiety sensitivity and trait anxiety both accounted for unique proportions of the variance in anxiety disorder symptoms. Altogether these findings are in agreement with those of previous research in adult and child populations, and further support the notion that anxiety sensitivity should be viewed as an unique factor of anxiety vulnerability. (C) 2000 Elsevier Science Ltd. All rights reserved.
\end{abstract}

Keywords: Anxiety sensitivity; Trait anxiety; Anxiety disorder symptoms; Depression; Normal adolescents

* Corresponding author. Tel.: +31-43-388-1264; fax: +31-43-367-0968.

E-mail address: p.muris@dep.unimaas.nl (P. Muris). 


\section{Introduction}

Anxiety sensitivity refers to the fear of anxiety-related sensations that are interpreted as having potentially harmful somatic, psychological, or social consequences, and hence give rise to significant anxiety (e.g., Taylor, 1995). Research in adult populations has provided evidence for the notion that anxiety sensitivity should be considered as a vulnerability factor to anxiety disorders, in particular panic disorder (e.g., Rachman, 1998).

Relatively few studies have examined the construct of anxiety sensitivity in children. In one of the first studies, Silverman et al. (1991) evaluated the validity of the Child Anxiety Sensitivity Index (CASI), which is a modification of the Anxiety Sensitivity Index (ASI; Reiss, Peterson, Gursky \& McNally, 1986), the most widely used instrument to measure anxiety sensitivity in adults. Results showed that anxiety sensitivity as indexed by the CASI correlates in a theoretically meaningful way with measures of fear and anxiety. Subsequent studies by Chorpita, Albano and Barlow (1996) and Weems, Hammond-Laurence, Silverman and Ginsburg (1998) investigated the incremental validity of the CASI and found evidence to suggest that anxiety sensitivity predicts variance of children's trait anxiety beyond that predicted by measures of manifest anxiety and fear. Further research by Rabian, Peterson, Richters and Jensen (1993) examined levels of anxiety sensitivity in children with anxiety disorders, children with externalizing disorders and children with no diagnosis. Results showed that children with anxiety disorders had significantly higher anxiety sensitivity scores than children with no disorders, whereas children with externalizing disorders scored in between. Lau, Calamari and Waraczynski (1996) studied the relationship between anxiety sensitivity and panic symptomatology in normal adolescents. These authors found significant associations between anxiety sensitivity and the number of panic attacks experienced, level of distress caused by panic symptoms, number of autonomic symptoms, and judged seriousness and negative cognitive appraisal of panic attacks. Kearney, Albano, Eisen, Allan and Barlow (1997) replicated these results in a clinical sample. In their study, children and adolescents with panic disorder were found to have higher levels of anxiety sensitivity than children and adolescents with non-panic anxiety disorders. Finally, recent factor analytic studies (Laurent, Schmidt, Catanzaro, Joiner \& Kelley, 1998; Silverman, Ginsburg \& Goedhart, 1999) seem to indicate that anxiety sensitivity in 7-16-year-old children can be conceptualized as a hierarchical construct consisting of a general factor (i.e., anxiety sensitivity) and two, three, or four specific lower-order factors (e.g., fear of physiological symptoms, fear of mental incapacity, etc.). Altogether, the results of research on anxiety sensitivity in children are largely in keeping with three main conclusions of studies that have investigated this construct in adults. First, anxiety sensitivity can be regarded as a unidimensional construct at a higher-order level, but seems to be multidimensional at a lowerorder level. Second, although related to fear, manifest anxiety, and trait anxiety, anxiety sensitivity seems to represent an unique domain of anxiety. Third, elevated levels of anxiety sensitivity are associated with the anxiety disorders but in particular with panic disorder (see for a comprehensive review, Taylor, 1995).

Besides anxiety sensitivity, trait anxiety is generally regarded as a vulnerability factor for the development of anxiety disorders (e.g., Eysenck, 1992). While it is clear that anxiety sensitivity and trait anxiety are intercorrelated, and that this is true for adult as well as child populations (e.g., Taylor, Koch \& Crockett, 1991; Silverman et al., 1991), there is consensus among researchers that both constructs are conceptually different from each other. Trait anxiety is regarded as the more 
general tendency to react anxiously to potentially anxiety-provoking stimuli, whereas anxiety sensitivity is viewed as the more specific tendency to react anxiously to one's own anxiety and anxiety-related sensations (see Taylor, 1995). Hence, it is generally assumed that anxiety sensitivity and trait anxiety each account for unique proportions of the variance in anxiety disorders symptomatology.

While the relationship between anxiety sensitivity and anxiety disorders has received considerable research attention, relatively little is known about the connection between anxiety sensitivity and depression. A number of studies in adult populations (Otto, Pollack, Fava, Uccello \& Rosenbaum, 1995; Taylor, Koch, Woody \& McLean, 1996) have shown that depressed patients had lower anxiety sensitivity scores than patients with panic disorder, comparable scores to patients with other anxiety disorders, but clearly higher scores than healthy controls. Weems, HammondLaurence, Silverman, and Ferguson (1997) provided evidence for the positive relation between anxiety sensitivity and depression in children. These authors showed that the correlation between anxiety sensitivity and depression remained significant even when controlling for levels of manifest anxiety (i.e., worry, physiological anxiety, and concentration).

The current study further examined the anxiety sensitivity construct in children. A large sample of normal Dutch adolescents aged 13-16 years $(n=819)$ completed the CASI (Silverman et al., 1991) as a measure of childhood anxiety sensitivity, the trait anxiety scale of the State-Trait Anxiety Inventory for Children (STAIC; Spielberger, 1973), the Spence Children's Anxiety Scale (SCAS; Spence, 1998) as an index of anxiety disorder symptoms, and the Children's Depression Inventory (CDI; Kovacs, 1981). The following research questions were addressed: (1) What is the factor structure of the CASI in normal adolescents of this age? (2) What is the relationship between anxiety sensitivity and trait anxiety? (3) What is the relationship between anxiety sensitivity, on the one hand, and symptoms of anxiety disorders and depression, on the other hand? and (4) Do anxiety sensitivity and trait anxiety declare unique proportions of variance in anxiety disorder symptoms and depression?

\section{Method}

\subsection{Subjects and procedure}

Eight-hundred-and-nineteen adolescents (426 boys and 393 girls; 14.2 years, SD=1.0) were recruited from a normal secondary school. Children completed questionnaires (see below) in their classrooms. The teacher and a research assistant were always available to provide assistance if necessary and to ensure confidential and independent responding.

\subsection{Questionnaires}

A 16-item version of the CASI (Silverman et al., 1991) was used to measure children's anxiety sensitivity, i.e., fear of different symptoms of anxiety. Example items are "It scares me when my heart beats fast", "It scares me when I feel nervous", and "It scares me when I feel shaky". CASI items correspond with the 16 items of the ASI for adults (Reiss et al., 1986), only the wording of some items has been changed to make them more understandable and relevant to children and 
adolescents (see Silverman et al., 1999). Children have to rate each item on a 4-point Likert scale with 1=never, 2=sometimes, 3=often, and 4=always. A total CASI score (range 16-64) can be computed by summing across the items.

The trait version of the State-Trait Anxiety Inventory for Children (STAIC; Spielberger, 1973) contains 20 items that have to be rated on a 3-point scale: 1=almost never, 2=sometimes, or $3=$ often. STAIC scores range between 20 and 60 with higher scores reflecting higher levels of trait anxiety.

The Spence Children's Anxiety Scale (SCAS; Spence, 1998) is a self-report questionnaire measuring anxiety disorder symptoms in children. The scale contains 38 items that can be allocated to the following subscales: generalized anxiety disorder (six items; e.g., "I worry that something bad will happen"), separation anxiety disorder (six items; e.g., "I feel scared when I have to sleep on my own"), social phobia (six items; e.g., "I feel afraid that I will make a fool of myself in front of people"), panic disorder and agoraphobia (nine items; e.g., "All of a sudden I feel really scared for no reason at all", "I am afraid of being in crowded places"), obsessive-compulsive disorder (six items; e.g., "I have to think of special thoughts to stop bad things from happening"), and fears of physical injury replacing specific phobias (five items; e.g., "I am scared of dogs"). SCAS items are rated on 4-point scales: never, sometimes, often, or always. These are scored $1,2,3$ and 4, respectively. SCAS total and subscale scores are computed by summing across relevant items.

The Children's Depression Inventory (CDI; Kovacs, 1981) is a commonly used self-report measure of depression symptoms in children. The scale consists of 27 items dealing with sadness, self-blame, loss of appetite, insomnia, interpersonal relationships and school adjustment. Children indicate whether items were $1=$ not true or $2=$ true for them. CDI total scores varied between 27 (no depression symptoms) and 54 (all depression symptoms present).

\subsection{Statistical analysis}

The Statistical Package for Social Sciences (SPSS) was used for computing descriptive statistics, correlations, and carrying out $t$-test comparisons. To examine the structure of the anxiety sensitivity questionnaire, confirmatory factor analysis was conducted, employing the structural equations modeling approach, EQS (Bentler, 1989). The results of exploratory factor analysis was used as the basis for the models that were tested by means of EQS (estimation method: ML). Based on previous research on the structure of anxiety sensitivity in children (Laurent et al., 1998; Silverman et al., 1999), ten models were tested in which anxiety sensitivity was represented as (1) a single factor, (2) two uncorrelated factors, (3) two correlated factors, (4) two factors loading on one higher-order factor, (5) three uncorrelated factors, (6) three correlated factors, (7) three factors loading on one higher-order factor, (8) four uncorrelated factors, (9) four correlated factors, and (10) four factors loading on one higher-order factor. EQS produces a wide range of goodnessof-fit indices of which the following were used in the present study; (a) chi square divided by degrees of freedom (with large sample sizes as in the current study, this value should be smaller than 4.00; the lower this value, the better the fit), (b) the Average Absolute Standardized Residuals (AASR; this value should be 0.05 or lower; the lower this value, the better the fit), (c) the Root Mean Square Error of Approximation (RMSEA; this value should be 0.05 or lower; the lower the value, the better the fit), (d) the Comparative Fit Index (CFI; this value should be 0.90 or 
higher for a good fit; the higher this value, the better the fit), (e) the Goodness of Fit Index (GFI; this value should be 0.90 or higher for a good fit; the higher the value, the better the fit) and (f) Akaike's Information Criterion (AIC; this is a relative measure: the model with the lowest value has the best fit). Factor analyses were carried out for the total sample and for boys and girls separately. As these analyses essentially revealed a similar pattern of findings, only the results for the total sample will be presented hereafter.

\section{Results}

\subsection{Descriptive statistics of the questionnaires}

Before addressing the main results, two remarks about the descriptive statistics of the various questionnaires are in order (see Table 1). First, the questionnaires generally had satisfactory internal consistency. That is, Cronbach's alphas were all well above 0.60 except for SCAS physical injury fears $(\alpha=0.56)$. Second, significant gender differences were found for the CASI $[t(697.3$, adjusted $d f)=6.4, P<0.001]$, STAIC [t(741.5, adjusted $d f)=7.7, P<0.001]$, SCAS total score $[t(725.1$, adjusted $d f)=8.0, P<0.001]$, SCAS generalized anxiety disorder $[t(758.4$, adjusted $d f)=6.7, P<0.001]$, SCAS separation anxiety disorder [ $t(749.0$, adjusted $d f)=6.7, P<0.001]$, SCAS social phobia $[t(774.3$, adjusted $d f)=5.4, P<0.001]$, SCAS panic disorder and agoraphobia $[t(692.2$, adjusted $d f)=6.3, P<0.001]$, SCAS physical injury fears $[t(695.7$, adjusted $d f)=11.7$, $P<0.001]$, and CDI [ $t(752.2$, adjusted $d f)=3.7, P<0.001]$. As shown in Table 1 , girls exhibited higher levels of anxiety sensitivity, trait anxiety, anxiety disorder symptoms, and depression than boys.

Table 1

Descriptive statistics (means, standard deviations, gender difference, and Cronbach's alphas) of the various questionnaires $^{\mathrm{a}}$

\begin{tabular}{lcrrc}
\hline & Total group $(n=819)$ & Boys $(n=426)$ & Girls $(n=393)$ & $\alpha$ \\
\hline CASI & $21.4(5.0)$ & $20.3(4.0)_{\mathrm{a}}$ & $22.5(5.7)_{\mathrm{b}}$ & 0.84 \\
STAIC & $28.3(6.9)$ & $26.5(5.9)_{\mathrm{a}}$ & $30.2(7.5)_{\mathrm{b}}$ & 0.90 \\
SCAS & & & & \\
$\quad$ Total score & $52.3(10.6)$ & $49.5(8.7)_{\mathrm{a}}$ & $55.3(11.6)_{\mathrm{b}}$ & 0.91 \\
Generalized anxiety disorder & $9.8(2.4)$ & $9.3(2.1)_{\mathrm{a}}$ & $10.4(2.6)_{\mathrm{b}}$ & 0.74 \\
Separation anxiety disorder & $7.5(1.6)$ & $7.1(1.4)_{\mathrm{a}}$ & $7.8(1.7)_{\mathrm{b}}$ & 0.60 \\
Social phobia & $8.9(2.3)$ & $8.5(2.1)_{\mathrm{a}}$ & $9.4(2.4)_{\mathrm{b}}$ & 0.67 \\
Panic disorder and agoraphobia & $10.8(2.7)$ & $10.3(2.1)_{\mathrm{a}}$ & $11.4(3.1)_{\mathrm{b}}$ & 0.78 \\
Obsessive-compulsive disorder & $8.3(2.4)$ & $8.1(2.2)_{\mathrm{a}}$ & $8.4(2.6)_{\mathrm{a}}$ & 0.71 \\
Physical injury fears & $7.0(2.0)$ & $6.2(1.5)_{\mathrm{a}}$ & $7.8(2.2)_{\mathrm{b}}$ & 0.56 \\
CDI & $29.6(3.7)$ & $29.2(3.2)_{\mathrm{a}}$ & $30.1(4.1)_{\mathrm{b}}$ & 0.83 \\
\hline
\end{tabular}

${ }^{a}$ CASI=Childhood Anxiety Sensitivity Index, STAIC=trait anxiety scale of the Spielberger State-Trait Anxiety Inventory for Children, SCAS=Spence Children's Anxiety Scale, CDI=Children's Depression Inventory. Means in the same row that do not share the same subscripts differ at $P<0.001$. 


\subsection{Factor structure of the CASI in normal adolescents}

Goodness-of-fit indices for the 10 tested models are presented in Table 2. As can be seen, Model 7 (three factors loading on one higher-order factor), Model 9 (four correlated factors), and Model 10 (four factors loading on one higher-order factor) provided excellent fits for the data. All fit indices for these models were satisfactory and indicative of a good fit: chi square/degrees of freedom ratios $<4.0$, AASRs $<0.05$, RMSEAs $\leq 0.05$, CFIs and GFIs $>0.90$, and these models clearly had the lowest AIC values.

Table 3 shows the factor loadings of CASI items in Model 7 (three factors, one higher-order factor) as obtained by means of confirmatory factor analysis. As can be seen, all 16 items loaded substantially (i.e., $\geq 0.35$ ) on one of the three lower-order factors, whereas the three factors in turn loaded convincingly (i.e., $\geq 0.79$ ) on the higher-order factor (i.e., anxiety sensitivity). On the basis of their content, the three lower-order factors were labeled as: (1) Fear of Physiological Arousal, (2) Fear of Losing Control and Social Evaluation and (3) Fear of Mental Incapacity. Internal consistency reliability of these three CASI factors appeared to be sufficient, Cronbach's alpha coefficients were $0.80,0.62$, and 0.77 , respectively.

Factor loadings of CASI items in Model 10 (four factors, one higher-order factor) are shown in Table 4. All items loaded substantially (i.e., $\geq 0.40$ ) on one of the four lower-order factors and the four factors in turn loaded convincingly (i.e., $\geq 0.59$ ) on the higher-order factor (anxiety sensitivity). The four factors were labeled as: (1) Fear of Physiological Arousal, (2) Fear of Losing Control, (3) Fear of Mental Incapacity, and (4) Fear of Social Evaluation. Internal consistency for these four factors were $0.82,0.46,0.75$. and 0.34 , respectively. Thus, compared to the above described 3-factor model, the factor Fear of Losing Control and Social Evaluation was found to split into two factors (i.e., Fear of Losing Control and Fear of Social Evaluation).

As mentioned earlier, Model 9 in which anxiety sensitivity was represented as four correlated factors also provided an excellent fit. One could interpret this finding as evidence against the hierarchical structure of the anxiety sensitivity construct. However, it is likely that this finding

Table 2

Goodness-of-fit indices for each model of the structure of the CASI ${ }^{\mathrm{a}}$

\begin{tabular}{|c|c|c|c|c|c|c|c|}
\hline & & $\chi^{2} / d f$ & AASR & RMSEA & CFI & GFI & AIC \\
\hline Model 1 & One factor & 4.84 & 0.04 & 0.07 & 0.89 & 0.92 & 295.3 \\
\hline Model 2 & Two uncorrelated factors & 8.53 & 0.13 & 0.10 & 0.78 & 0.90 & 679.2 \\
\hline Model 3 & Two correlated factors & 4.07 & 0.03 & 0.06 & 0.91 & 0.94 & 213.1 \\
\hline Model 4 & Two factors, one higher-order factor & 4.11 & 0.03 & 0.06 & 0.91 & 0.94 & 215.1 \\
\hline Model 5 & Three uncorrelated factors & 9.89 & 0.16 & 0.10 & 0.74 & 0.87 & 820.3 \\
\hline Model 6 & Three correlated factors & 5.58 & 0.09 & 0.08 & 0.87 & 0.93 & 368.6 \\
\hline Model 7 & Three factors, one higher-order factor & 3.36 & 0.03 & 0.05 & 0.93 & 0.95 & 137.7 \\
\hline Model 8 & Four uncorrelated factors & 10.07 & 0.16 & 0.11 & 0.73 & 0.86 & 839.1 \\
\hline Model 9 & Four correlated factors & 3.10 & 0.03 & 0.05 & 0.94 & 0.96 & 108.1 \\
\hline Model 10 & Four factors, one higher-order factor & 3.13 & 0.03 & 0.05 & 0.94 & 0.95 & 113.1 \\
\hline
\end{tabular}

${ }^{\text {a }}$ CASI=Childhood Anxiety Sensitivity Index. AASR=Average Absolute Standardized Residuals, RMSEA=Root Mean Square Error of Approximation, CFI=Comparative Fit Index, GFI=Goodness of Fit Index, AIC=Akaike's Information Criterion. 
Table 3

Factor loadings of CASI items as obtained by confirmatory factor analysis for Model 7: three factors, one higherorder factor ${ }^{\mathrm{a}}$

\begin{tabular}{|c|c|c|c|}
\hline & \multicolumn{3}{|c|}{ Factor labels $^{\mathrm{b}}$} \\
\hline & 1 & 2 & 3 \\
\hline Scares me when heart beats fast (6) & 0.72 & & \\
\hline Unusual feeling in body scares me (14) & 0.69 & & \\
\hline When heart beats fast worry something wrong (9) & 0.65 & & \\
\hline Scares me when trouble catch breath (10) & 0.61 & & \\
\hline Scares me when feel like throw up (8) & 0.58 & & \\
\hline Scares me when feel faint (4) & 0.57 & & \\
\hline When stomach hurt worry really sick (11) & 0.53 & & \\
\hline Important to stay in control (5) & & 0.55 & \\
\hline Embarrasses when stomach growls (7) & & 0.48 & \\
\hline Other kids tell when I feel shaky (13) & & 0.39 & \\
\hline Don't want other to know afraid (1) & & 0.35 & \\
\hline Scares me when feel nervous (16) & & & 0.69 \\
\hline When can't schoolwork worry crazy (2) & & & 0.67 \\
\hline When afraid worry might be crazy (15) & & & 0.65 \\
\hline Scares me when can't keep mind on schoolwork (12) & & & 0.61 \\
\hline Scares me when feel shaky (3) & & & 0.61 \\
\hline Loading of factor on higher-order factor & 0.87 & 0.79 & 0.94 \\
\hline
\end{tabular}

${ }^{\text {a }}$ CASI=Childhood Anxiety Sensitivity Index.

b Factor Labels; (1) Fear of Physiological Arousal, (2) Fear of Losing Control and Social Evaluation and (3) Fear of Mental Incapacity.

was due to the fact that the factors 2 and 4 were rather unreliable and as a consequence less strong indicators of the higher-order factor (i.e., anxiety sensitivity). This may have prevented Model 10 (i.e., the hierarchical model) from yielding a superior fit above Model 9.

\subsection{Relationship between anxiety sensitivity and trait anxiety}

The correlation (corrected for gender) between anxiety sensitivity and trait anxiety was substantial and positive: $r=0.72, P<0.001$.

\subsection{Relationship between anxiety sensitivity and anxiety disorder symptoms and depression}

The left column of Table 5 shows correlations (corrected for gender) between anxiety sensitivity, on the one hand, and anxiety disorder symptoms (SCAS) and depression (CDI), on the other hand. As can be seen, anxiety sensitivity was significantly related to panic disorder and agoraphobia $(r=0.71, P<0.001)$, other anxiety disorder symptoms $[r$ s between 0.44 (physical injury fears) and 0.79 (total score), all $P \mathrm{~s}<0.001]$ and depression $(r=0.49, P<0.001)$. As can be seen in the right column of Table 5, STAIC trait anxiety was also significantly associated with anxiety disorder symptoms and depression ( $r$ s between 0.43 and 0.81 , all $P_{\mathrm{s}}<0.001$ ). 
Table 4

Factor loadings of CASI items as obtained by confirmatory factor analysis for Model 10: four factors, one higherorder factor $^{\mathrm{a}}$

\begin{tabular}{|c|c|c|c|c|}
\hline & \multicolumn{4}{|c|}{ Factor labels $^{\mathrm{b}}$} \\
\hline & 1 & 2 & 3 & 4 \\
\hline Scares me when heart beats fast (6) & 0.72 & & & \\
\hline Unusual feeling in body scares me (14) & 0.68 & & & \\
\hline When heart beats fast worry something wrong (9) & 0.64 & & & \\
\hline Scares me when trouble catch breath (10) & 0.61 & & & \\
\hline Scares me when feel shaky (3) & 0.60 & & & \\
\hline Scares me when feel like throw up (8) & 0.58 & & & \\
\hline Scares me when feel faint (4) & 0.57 & & & \\
\hline When stomach hurt worry really sick (11) & 0.52 & & & \\
\hline Important to stay in control (5) & & 0.75 & & \\
\hline Don't want other to know afraid (1) & & 0.40 & & \\
\hline Scares me when feel nervous (16) & & & 0.69 & \\
\hline When afraid worry might be crazy (15) & & & 0.68 & \\
\hline When can't schoolwork worry crazy (2) & & & 0.67 & \\
\hline Scares me when can't keep mind on schoolwork (12) & & & 0.63 & \\
\hline Embarrasses when stomach growls (7) & & & & 0.51 \\
\hline Other kids tell when I feel shaky (13) & & & & 0.40 \\
\hline Loading of factor on higher-order factor & 0.88 & 0.59 & 0.90 & 0.82 \\
\hline
\end{tabular}

${ }^{a}$ CASI=Childhood Anxiety Sensitivity Index.

b Factor labels; (1) Fear of Physiological Arousal, (2) Fear of Losing Control, (3) Fear of Mental Incapacity, and (4) Fear of Social Evaluation.

Table 5

Correlations (controlling for gender) between anxiety sensitivitity (CASI) and trait anxiety (STAIC), on the one hand, and anxiety disorder symptoms (SCAS) and depression (CDI), on the other hand ${ }^{a}$

\begin{tabular}{lll}
\hline & CASI & STAIC \\
\hline SCAS & & \\
Total score & $0.79_{\mathrm{a}}$ & $0.81_{\mathrm{a}}$ \\
Generalized anxiety disorder & $0.70_{\mathrm{a}}$ & $0.72_{\mathrm{a}}$ \\
Separation anxiety disorder & $0.57_{\mathrm{a}}$ & $0.61_{\mathrm{b}}$ \\
Social phobia & $0.62_{\mathrm{a}}$ & $0.69_{\mathrm{b}}$ \\
Panic disorder and agoraphobia & $0.71_{\mathrm{a}}$ & $0.66_{\mathrm{b}}$ \\
Obsessive-compulsive disorder & $0.61_{\mathrm{a}}$ & $0.62_{\mathrm{a}}$ \\
Physical injury fears & $0.44_{\mathrm{a}}$ & $0.43_{\mathrm{a}}$ \\
CDI & $0.49_{\mathrm{a}}$ & $0.63_{\mathrm{b}}$ \\
\hline
\end{tabular}

${ }^{a} N=819$. All correlations were significant at $P<0.001$. CASI=Childhood Anxiety Sensitivity Index, STAIC=trait anxiety scale of the Spielberger State-Trait Anxiety Inventory for Children, SCAS=Spence Children's Anxiety Scale, $\mathrm{CDI}=$ Children's Depression Inventory. Correlations in the same row that do not share the same subscripts differ at $P<0.05$. 
The correlations between anxiety sensitivity and SCAS/CDI were compared to those between trait anxiety and SCAS/CDI using the method of comparing correlations as described by McNemar (1969). Results showed that trait anxiety was more strongly related to separation anxiety disorder $(t=-2.0, P<0.05)$, social phobia $(t=-3.9, P<0.001)$, and depression $(t=-6.9, P<0.001)$, whereas anxiety sensitivity was more substantially connected to panic disorder and agoraphobia $(t=2.8$, $P<0.01$; see Table 5).

\subsection{Unique contribution of anxiety sensitivity and trait anxiety to anxiety disorder symptoms and depression}

Partial correlations (corrected for gender) between anxiety sensitivity and anxiety disorder symptoms/depression while controlling for levels of trait anxiety are displayed in the left column of Table 6. Two conclusions can be drawn from this analysis. First, although correlations attenuated, anxiety sensitivity still correlated significantly with SCAS anxiety disorder symptoms, in particular with panic disorder and agoraphobia. Second, the correlation between anxiety sensitivity and depression disappeared when the influence of trait anxiety was cancelled out. Partial correlations between trait anxiety and anxiety disorder symptoms/depression while controlling for anxiety sensitivity are shown in the right column of Table 6. As can be seen, all correlations, even that between trait anxiety and depression, remained significant.

Comparisons of the partial correlations revealed that trait anxiety was more strongly associated with separation anxiety disorder $(t=-2.0, P<0.05)$, social phobia $(t=-4.9, P<0.001)$, and depression $(t=7.3, P<0.001)$, whereas anxiety sensitivity was more convincingly connected to panic disorder and agoraphobia $(t=3.6, P<0.001)$.

\section{Table 6}

Partial correlations (controlling for gender) calculated separately for anxiety sensitivitity (CASI) and trait anxiety (STAIC) with measures of anxiety disorder symptoms (SCAS) and depression (CDI) while holding the other one con$\operatorname{stant}^{\mathrm{a}}$

CASI (controlling for trait anxiety) STAIC (controlling for anxiety sensitivity)

$\begin{array}{lll}\text { SCAS } & & \\ \text { Total score } & 0.51_{\mathrm{a}} & 0.56_{\mathrm{a}} \\ \text { Generalized anxiety disorder } & 0.37_{\mathrm{a}} & 0.44_{\mathrm{a}} \\ \text { Separation anxiety disorder } & 0.25_{\mathrm{a}} & 0.34_{\mathrm{b}} \\ \text { Social phobia } & 0.24_{\mathrm{a}} & 0.45_{\mathrm{b}} \\ \text { Panic disorder and agoraphobia } & 0.45_{\mathrm{a}} & 0.30_{\mathrm{b}} \\ \text { Obsessive-compulsive disorder } & 0.30_{\mathrm{a}} & 0.33_{\mathrm{a}} \\ \text { Physical injury fears } & 0.20_{\mathrm{a}} & 0.19_{\mathrm{a}} \\ \text { CDI } & 0.06_{\mathrm{a}}^{\mathrm{b}} & 0.46_{\mathrm{b}}\end{array}$

a $N=819$.

b Non-significant correlation, all other correlations were significant at $P<0.001$. CASI=Childhood Anxiety Sensitivity Index, STAIC=trait anxiety scale of the Spielberger State-Trait Anxiety Inventory for Children, SCAS=Spence Children's Anxiety Scale, CDI=Children's Depression Inventory. Correlations in the same row that do not share the same subscripts differ at $P<0.05$. 


\section{Discussion}

The current study examined the anxiety sensitivity construct in a large sample of normal Dutch adolescents aged 13-16 years. Results can be catalogued as follows: (1) structural equation modeling indicated that anxiety sensitivity as measured by the CASI can best be conceptualized as a hierarchical construct with one higher-order factor (i.e., anxiety sensitivity) and three or four lower-order factors; (2) anxiety sensitivity and trait anxiety were strongly correlated; (3) anxiety sensitivity was substantially connected to anxiety disorder symptoms, in particular panic disorder and agoraphobia, and depression; and (4) anxiety sensitivity and trait anxiety were both found to account for unique proportions of the variance in anxiety disorder symptoms. However, in the case of depression, anxiety sensitivity no longer declared a significant proportion once the influence of trait anxiety was partialled out.

The present findings on the factor structure of anxiety sensitivity are largely in line with those of previous studies in both child and adult samples (Cox, Parker \& Swinson, 1996; Laurent et al., 1998; Silverman et al., 1999; Taylor \& Cox, 1998a, b; Zinbarg, Barlow \& Brown, 1997). More specifically, anxiety sensitivity seems to be a hierarchically organized construct that is unitary at a higher-order level but multidimensional at a lower-order level (see for a review, Taylor, 1995). There is still some debate about the exact number of lower-order factors in the anxiety sensitivity construct. In line with a previous study of Silverman et al. (1999), the present data point out that the optimal model for childhood anxiety sensitivity as indexed by the CASI is a hierarchical structure with three or four lower-order factors. However, it seems to be the case that the 16 items of the CASI are too few to reliably tap the lower-order factors of anxiety sensitivity (see supra) and that the inclusion of additional items is necessary to disclose the exact structure of the anxiety sensitivity construct in children.

Anxiety sensitivity and trait anxiety were both found to account for unique proportions of the variance of anxiety disorder symptoms. Results also suggested that anxiety sensitivity is more convincingly associated with panic disorder and agoraphobia, whereas trait anxiety is more strongly connected to symptoms of social phobia and separation anxiety disorder. Although it should be acknowledged that the current study was cross-sectional in nature and hence does not provide evidence for any kind of causal association, the data are supportive of the notion that anxiety sensitivity and trait anxiety should be viewed as distinct vulnerability factors that have independent predictive power in the development of anxiety disorder symptoms.

The present study found a significant correlation between anxiety sensitivity and depression. However, when controlling for levels of trait anxiety, this correlation clearly attenuated and no longer attained statistical significance. Weems et al. (1997) also found a significant correlation between anxiety sensitivity and childhood depression, but noted that this correlation remained significant when general anxiety (as measured by the Revised Children's Manifest Anxiety Scale; Reynolds \& Richmond, 1978) was partialled out. Sample differences may account for these diverging results. That is, whereas Weems et al. (1997) relied on a sample of clinically referred children, the present study relied on a sample of normal adolescents with relatively low levels of depression.

In conclusion, the present data provide further support for the relevance of anxiety sensitivity in the study of childhood anxiety. Even when controlling for levels of trait anxiety, anxiety sensitivity accounted for significant proportions of the variance of anxiety disorder symptoms. This result 
suggests that anxiety sensitivity should be viewed as an unique factor of anxiety vulnerability. Future prospective studies are needed to further establish the role of anxiety sensitivity in the development of anxiety disorders in children and adolescents.

\section{References}

Bentler, P. M. (1989). EQS: structural equations program manual. Los Angeles, CA: BMDP Statistical Software Inc. Chorpita, B. F., Albano, A. M., \& Barlow, D. H. (1996). Child anxiety sensitivity index: considerations for children with anxiety disorders. Journal of Clinical Child Psychology, 25, 77-82.

Cox, B. J., Parker, J. D., \& Swinson, R. P. (1996). Anxiety sensitivity: confirmatory evidence for a multidimensional construct. Behaviour Research and Therapy, 34, 591-598.

Eysenck, M. W. (1992). Anxiety. The cognitive perspective. Hove: Lawrence Erlbaum.

Kearney, C. A., Albano, A. M., Eisen, A. R., Allan, W. D., \& Barlow, D. H. (1997). The phenomenology of panic disorder in youngsters: an empirical study of a clinical sample. Journal of Anxiety Disorders, 11, 49-62.

Kovacs, M. (1981). Rating scales to assess depression in school-aged children. Acta Paedopsychiatrica, 46, 305-315.

Lau, J. J., Calamari, J. E., \& Waraczynski, M. (1996). Panic attack symptomatology and anxiety sensitivity in adolescents. Journal of Anxiety Disorders, 19, 355-364.

Laurent, J., Schmidt, N. B., Catanzaro, S. J., Joiner, T. E., \& Kelley, A. M. (1998). Factor structure of a measure of anxiety sensitivity in children. Journal of Anxiety Disorders, 12, 307-331.

McNemar, Q. (1969). Psychological statistics. (4th ed.). New York: Wiley.

Otto, M. W., Pollack, M. H., Fava, M., Uccello, R., \& Rosenbaum, J. F. (1995). Elevated anxiety sensitivity index scores in patients with major depression: correlates and changes with antidepressant treatment. Journal of Anxiety Disorders, 9, 117-123.

Rabian, B., Peterson, R. A., Richters, J., \& Jensen, P. S. (1993). Anxiety sensitivity among anxious children. Journal of Clinical Child Psychology, 22, 441-446.

Rachman, S. (1998). Anxiety. Hove: Psychology Press.

Reiss, S., Peterson, R. A., Gursky, D. M., \& McNally, R. J. (1986). Anxiety sensitivity, anxiety frequency, and the prediction of fearfulness. Behaviour Research and Therapy, 24, 1-8.

Reynolds, C. R., \& Richmond, B. O. (1978). What I think and feel: a revised measure of children's manifest anxiety. Journal of Abnormal Child Psychology, 6, 271-280.

Silverman, W. K., Fleisig, W., Rabian, B., \& Peterson, R. A. (1991). Childhood anxiety sensitivity index. Journal of Clinical Child Psychology, 20, 162-168.

Silverman, W. K., Ginsburg, G. S., \& Goedhart, A. W. (1999). Factor structure of the childhood anxiety sensitivity index. Behaviour Research and Therapy, 37, 903-917.

Spence, S. H. (1998). A measure of anxiety symptoms among children. Behaviour Research and Therapy, 36, 545-566.

Spielberger, C. D. (1973). Manual for the state-trait anxiety inventory for children. Palo Alto, CA: Consulting Psychologists Press.

Taylor, S. (1995). Anxiety sensitivity: theoretical perspectives and recent findings. Behaviour Research and Therapy, $33,243-258$.

Taylor, S., \& Cox, B. J. (1998a). Anxiety sensitivity: multiple dimensions and hierarchic structure. Behaviour Research and Therapy, 36, 37-51.

Taylor, S., \& Cox, B. J. (1998b). An expanded anxiety sensitivity index: evidence for a hierarchic structure in a clinical sample. Journal of Anxiety Disorders, 12, 463-484.

Taylor, S., Koch, W. J., \& Crockett, D. J. (1991). Anxiety sensitivity, trait anxiety, and the anxiety disorders. Journal of Anxiety Disorders, 6, 293-311.

Taylor, S., Koch, W. J., Woody, S., \& McLean, P. (1996). Anxiety sensitivity and depression: how are they related? Journal of Abnormal Psychology, 105, 474-479.

Weems, C. F., Hammond-Laurence, K., Silverman, W. K., \& Ginsburg, G. S. (1998). Testing the utility of the anxiety sensitivity construct in children and adolescents referred for anxiety disorders. Journal of Clinical Child Psychology, 27, 69-77. 
Weems, C. F., Hammond-Laurence, K., Silverman, W. K., \& Ferguson, C. (1997). The relation between anxiety sensitivity and depression in children and adolescents referred for anxiety. Behaviour Research and Therapy, 35, 961-966.

Zinbarg, R. E., Barlow, D. H., \& Brown, T. A. (1997). Hierarchical structure and general factor saturation of the anxiety sensitivity index. Psychological Assessment, 9, 277-284. 